speculations which have been put forward from time to time to account for the behaviour of silver halide emulsions. The most important step in this work has been the preparation and use of large single crystals of silver bromide in the form of thin parallel slabs. These can be obtained either strained or, by an annealing process, strain-free.

The results of sensitization by immersion in gelatin solutions, by digestion with gelatin solutions which could be modified by the addition of reducing substances, sulphur-containing sensitizers and potassium chloro-iridite, were described. Chemical sensitization appears to arise from silver, gold or silver sulphide produced at strained or roughened regions on the surfaces of the crystals. By direct deposition of silver and gold on the surfaces, it was possible to check this view, and silver films could also be converted to silver sulphide. On exposure of silver bromide to light, halogen atoms are released, and ohemical sensitizers function by reaction with the released halogen. The recent results have brought into prominence some of the older theories of sensitivity. A lively discussion, opened by $\mathrm{Mr}$. R. C. M. Smith (Ilford, Ltd.), followed the paper, and gave Dr. Mitchell the opportunity to expand his account of certain aspects of the work.

The second paper, given by Dr. C. H. Bamford (Courtaulds Fundamental Research Laboratory, Maidenhead), was on "Synthetic Polypeptides", and in it the work which has been carried out at Maidenhead was reviewed and related to the behaviour of proteins. The configuration of polypeptide chains can be examined by such physical methods as absorption of polarized infra-red radiation, which enables the directions of the $-\mathrm{NH}$ and $-\mathrm{CO}$ groups to be determined, by X-ray diffraction spectra, where certain polypeptides give results in close agreement with those to be expected for the 3.7 helical structures proposed by Pauling, and by optical rotation. Synthetic polypeptides occur in two configurations: $\alpha$, referred to above, with intrachain hydrogen bonding; and $\beta$, an extended form with interchain hydrogen bonding. These eorrespond closely with structures found for natural proteins such as keratin and silk; but an analogue for collagen has not been found yet. The discussion on this paper was opened by Mr. A. G. Ward (British Gelatine and Glue Research Association).

A. G. WARD

\section{WATER POLLUTION RESEARCH IN BRITAIN}

$\mathrm{T}$ those whose work or interest lies in river. pollution prevention, water treatment, and sewage and trade wastes purification, the study of the annual reports of the Water Pollution Research Board and of the Director of Research is at once a necessity and a pleasure. The report for $1954^{*}$ easily maintains the interest and information that have characterized previous reports.

A notable event of the year was the completion and occupation of the new laboratories at Stevenage, Hertfordshire, which now house all the staff who were previously working at Watford, Garston, Birmingham, Coventry and Tilbury. Thus for the first time since the formation of the organization in 1927 , all the

- Department of Scientific and Industrial Research. Report of the Water Pollution Research Board, with the Report of the Director of Water Pollution Research for the year 1954. Pp. vi $+65+4$ plates. (London: H.M. Stationery Office, 1955.) 3s. net. staff aro together in one building-a great advantage for future work. The new laboratories have a number of novol features; among the many ficitities may be instanced a small pumping station, which can deliver up to 50,000 gallons of sewage daily to experimental plant (see also Nature, June 25, p. 1105).

The largest section of the report comprises an account of the progress made in the complex survey of the Thames Estuary. Here it was found necessealy to undertake the fundamental task of redetermining the values of the solubility of oxygen in water, over a range of temperatures and salinities, in equilibrium with moist air of normal composition at sea-level. The values so obtained were found to be $3-4$ per cent lower than those commonly accepted hitherto. Part of this work involved the checking of the wellknown Winkler titrimetric method for the determination of dissolved oxygen against \& reference gasometric method, establishing that the former is without appreciable error. Other studies included a statistical examination of the chemical records of the London County Council concerning the condition of the Thames, and the factors controlling the balance of oxygen in the estuary water-that is to say, the amount of fresh water entering at Teddington, the absorption of oxygen from the atmosphere under various surface conditions, the effect of synthetic detergents upon the absorption and the rate of oxidation of polluting matter, including the effect of bottom deposits removed by dredging. Both fieldinvestigations and laboratory experiments have now been terminated; but the final conclusions await the completion of the many lengthy calculations that have to be made.

A further section of the report deals with the effects of pollution on fish. The Laboratory has assisted the Ministry of Agriculture and Fisheries in a survey of the River Colne, principally regarding the effect of sewage effluent upon fish life. Laboratory experiments are being continued on the degree of toxicity of ammonia, carbon dioxide and synthetic detergents. It appears that the degree of toxicity is frequently related to the amount of dissolved oxygen presentfish can survive doses of toxic substances in wellaerated water that would be fatal in poorly oxygenated water.

In the section on sewage, an account is given of the examination of surface run-off water from a housing estate, the conclusion being that this water was not of a very polluting nature apart from its rather high content of suspended solids. The biological filtration of sewage is discussed as regards periodicity of dosing and efficiency of filters, and also the work so far done on the effect of synthetic detergents upon sewage treatment, where quantitative information on the subject is by no means abundant.

A useful piece of work has been done in conjunction with the Government Laboratory : that of reviewing methods for determining concentrations of various metals in waste waters and effluents down to 0.1 p.p.m. The methods suggested are due to be incorporated in the second edition of "Methods of Chemical Analysis as Applied to Sewage and Sewage Effluents" to be published by the Ministry of Housing and Local Government.

Investigations have been continued concerning the removal of cyanides from industrial waste waters by biological filtration; the organism responsible has been isolated and described. Biological destruction of cyanide in mixed plating wastes has been shown to be a practical method for dealing with such 
wastes, and if the information resulting from this research is properly acted upon by the industries concerned, a potent source of pollution will be greatly reduced. Experiments on the anaerobic digestion of partially neutralized waste liquor from the kiering of cotton were also continued. This method of treatment is a possible one for pre-treatment before discharge to a public sewer, having the merit first of requiring loss space than a percolating filter to effect the same degre $\theta$ of improvement, and secondly of the ability to treat undiluted kier liquor, whereas for a percolating filter the liquor would require considerable dilution.

The section on water is very brief. Experiments are described on the removal of fluoride from water by passage through a column of activated alumina. The reason for the complete blockage of two slow sand-filters was investigated and found to be due to deposited crystals of calcium carbonate which had bound the sand grains together, the deposit having been induced by loss of carbon dioxide from the water during previous aeration.

Lastly the report emphasizes that an important part of the Laboratory's activities is now concerned with the development of automatic equipment. A noteworthy achievement has been the production of an instrument for the continuous recording of the dissolved oxygen content of a stream of water, thus giving valuable information about fluctuations that would usually be missed by the methods of intermittent sampling that otherwise have to be employed.

\section{STANFORD RESEARCH INSTITUTE, CALIFORNIA \\ REPORT FOR 1954}

$\mathrm{T}$ HE annual report for 1954 of the Stanford Research Institute, California*, records an increase of 242 in the staff during the year, and, of these, 165 have professional training and five to ten years of industrial experience. The staff now totals 916 , and the revenue has increased by 40 per cent to 7.57 million dollars. Contract research is now being conducted at the rate of 8.5 million dollars a year, and the number of research projects has increased from 382 to 478 , of which 297 were for private business, 128 for the Government and 53 were sponsored by the Institute as part of its plan for aiding the technological and economic development of the western part of the United States. In terms of dollars, the ratio of commercial projects to government projects was 54:46-an almost exact reversal of the ratio in 1953.

The 53 public service projects include studies of air pollution and high-temperature materials, of industrial water resources in California and of surface tension in solids; research on human engineering in industry; the effect of $\gamma$-radiation on high polymers; a survey of industrial land use in the Portland area; and the production of such reference works as the "Western Resources Handbook", "The Chemical Economics Handbook" and "The Directory of Western Chemical Producers". The Institute also sponsored symposia on the automatic production of electronic equipment, on social science for industry and on area development problems.

* Stanford Research Institute: Annual Report for 1954. Pp. 48. (Stanford, Calif.: Stanford Research Institute, 1955.)
In the Engineering Division electronics claims the largest share of attention, particularly the theoretical analysis of antenna systems, the design and manufacture of prototypes and the performance of radiation systems. The Physical Sciences Division has dealt with the production of chemicals from petroleum, utilization of wood waste, tallow, bagasse and fish waste, as well as the properties and applications of polymers, the storage and utilization of solar energy, the effect of infra-red radiation on chemical reactions, the use and control of sound waves and with the weapons-effect programme. The Division is also engaged in biochemical research and on problems in nutrition, microbiology, physiology and toxicology, while expansion into pharmacology is in progress. The Economics Division is concerned with three broad categories of work : the economic analysis of problems for specific companies ; the examination of specific functions, such as the application of electronic data-handling equipment to accounting and clerical operations, the application of operational research in management and the industrial application of social science; and the use of economic surveys in area development, including also the location and protection of plant, military logistics and weapons. system evaluation.

In the Poulter Laboratories contributions have been made to the understanding of shock waves and detonations which have increased the effectiveness of explosives both for military purposes and in mining, agriculture and demolition. 'The Institute's work on defence against nuclear bombs has shown that earthcovered steel-arch structures above ground provide a significant level of protection at economical cost ; but that most ordinary structures not speoifically designed for the purpose are not significantly strengthened against blast by earth cover. Work on rocket liners has shown that detonation in tubes can be limited by absorbing compression-wave energy at the walls and, in work on graphite nozzles for liquid fuel rockets, a new technique for converting graphite to metallic carbide for an appreciable depth has given promise. A non-destructive test device, called a stub meter, for the plastic-adhesive bonded sandwich has been developed by the Institute physicists. Ten common weeds, grown under controlled conditions, have now been standardized as indicators of atmospheric pollution by hydrogen fluoride, sulphur dioxide, hydrogen sulphide, ammonia, chlorine and oxides of nitrogen. Under a project sponsored by the Southern Pacific Co., the hydrofriction system for freight cars has been developed to distribute the impact of energy more evenly or at a more constant rate by new shock-absorbing mechanisms.

\section{METABOLISM OF RADIOACTIVE SUGARS}

$\mathrm{H}$ K. PORTER and L. H. May have followed the uptake and utilization of radioactive sugars by tobacco leaf disks (J. Exp. Bot., 6, 16, 43; 1955). When destarched tobacco-leaf disks were floated on 5 per cent $(\mathrm{w} / \mathrm{v})$ solutions of sucrose uniformly labelled with carbon-14 in either the glucose or fructose moiety, and on invert sugar in which one hexose only was so labelled, in an atmosphere of oxygen at $25^{\circ} \mathrm{C}$., seventy-five per cent of the sugar lost from the external solutions was recovered as starch, sucrose, fructose, glucose and carbon dioxide. 